\title{
Mechanisms and Prevention of Vertical Transmission in Chronic Viral Hepatitis
}

\author{
Marianna G. Mavilia* and George Y. Wu \\ Department of Medicine, Division of Gastroenterology-Hepatology, University of Connecticut Health Center, Farmington, CT, USA
}

\begin{abstract}
Vertical transmission (VT) is the primary route of transmission of viral hepatitis in children. The rate of VT ranges from $1-28 \%$ with hepatitis B virus (HBV) and $3-15 \%$ with hepatitis $\mathrm{C}$ virus (HCV). VT for both viruses can occur during the intrauterine or peripartum period. VT of HBV primarily occurs by intrauterine transmission (IUT). Hepatitis B surface antigen is unable to cross the placenta and, therefore, relies on processes like transplacental leakage, placental infection, cellular transmission by peripheral blood mononuclear cells, and germline transmission. HCV can also infect the fetus by IUT. Both viruses also have the potential for transmission during delivery, when there is increase chance of maternal-fetal blood exposure. HBV and HCV share some common risk factors for VT, including maternal viral load, human immunodeficiency virus co-infection and neonatal sex. Prevention of VT differs greatly between HBV and HCV. There are several alternatives for prevention of HBV VT, including antiviral medications during the third trimester of pregnancy and HBV vaccine, as well as hepatitis $B$ immunoglobulin administration to infants post-partum. In contrast, there are no preventative interventions available for HCV. Despite these differences, the key to prevention with both viruses is screening women prior to and during pregnancy.
\end{abstract}

Citation of this article: Mavilia MG, Wu GY. Mechanisms and prevention of vertical transmission in chronic viral hepatitis. J Clin Transl Hepatol 2017;5(2):119-129. doi: 10. 14218/JCTH.2016.00067.

\section{Introduction}

Chronic viral hepatitis remains a significant global health concern. In children, vertical transmission (VT) is the primary route of transmission of viral hepatitis. ${ }^{1-3}$ Currently, there are limited data available on viral hepatitis in pregnancy

Keywords: Vertical transmission; Hepatitis B; Hepatitis C; Mechanisms; Prevention.

Abbreviations: C-section, cesarean section; HBCAg, hepatitis B core antigen; $\mathrm{HBeAg}$, hepatitis B envelope antigen; HBIG, hepatitis B immunoglobulin; HBsAb, hepatitis B surface antibodies; HBsAg, hepatitis B surface antigen; HBV, hepatitis $B$ virus; $\mathrm{HCAb}$, hepatitis $C$ antibody; HCV, hepatitis $C$ virus; HIV, human immunodeficiency virus; IUT, intrauterine transmission; PBMCs, peripheral blood mononuclear cells; ROM, rupture of membranes; VT, vertical transmission.

Received: 22 November 2016; Revised: 29 March 2017; Accepted: 31 March 2017

*Correspondence to: Marianna G. Mavilia, Department of Medicine, University of Connecticut Health Center, 263 Farmington Ave, Farmington, CT 06032, USA. Tel: +1-860-679-2509, Fax: +1-860-679-6582, E-mail: mmavilia@uchc.edu and VT. Often, studies are limited by ethical concerns surrounding pregnancy and fetal well-being. While many risk factors for VT have been identified, the underlying pathophysiology of each are not well known. Overall, our understanding of the mechanisms of VT of chronic viral hepatitis is poor. The purpose of this review is to clarify what is currently known about the mechanisms of VT of both hepatitis $B$ virus (HBV) and hepatitis $\mathrm{C}$ virus (HCV).

\section{HBV}

\section{Epidemiology}

Approximately 370 million people are infected with chronic HBV worldwide. ${ }^{4}$ The prevalence of chronic HBV infection varies by geographical region, affecting less than $2 \%$ in the United States and Western Europe, $2-8 \%$ in the Mediterranean and South America and up to $20 \%$ in Asia and Africa. ${ }^{5}$ In infants and children, HBV is largely acquired by VT. If exposed to $\mathrm{HBV}$, neonates have a $90 \%$ risk of acquiring chronic HBV infection, whereas adults have a $5-10 \%$ chance of developing chronic infection. ${ }^{1,3,6}$ This vast contrast speaks to the differences in immune response observed in children versus adults.

The reported rates of VT range between $1 \%$ and $28 \%{ }^{7-17}$ (Table 1 ). There are a number of factors that impact the rate of VT, which will be discussed in greater detail below. One primary difference between these studies is the method used to diagnose HBV infection in neonates.

\section{Diagnostic criteria}

There is no universally accepted standard for the diagnosis of HBV infection in infants. ${ }^{16}$ This accounts for the wide range in rates of VT $(1-28 \%)^{7-17}$ seen among HBV studies. The most commonly used diagnostic markers are HBV DNA, hepatitis B surface antigen ( $\mathrm{HBsAg}$ ) and hepatitis $B$ envelope antigen (HBeAg). ${ }^{16}$ HBV DNA gives a direct measure of the presence of viral infection, while $\mathrm{HBsAg}$ and $\mathrm{HBeAg}$ provide indirect measurements. ${ }^{16}$

There is some controversy in the literature about the use of these markers for diagnosis of HBV infection. Some studies use HBsAg and/or HBV DNA positivity at certain time points as criteria for infection. ${ }^{8,11,14,17}$ Other studies suggest that the presence of these markers at birth may be transient and do not indicate a definite infection. ${ }^{1}$ Chen et al. ${ }^{7}$ found that seropositivity of both HBsAg and HBV DNA resolved after 12 months in $81.3 \%$ of cases, suggesting a VT rate of $18.7 \%$. That study proposed hepatitis B surface antibody (HBsAb) as a more accurate marker of exposure. ${ }^{7}$ Although the study was well controlled with recruitment of only anti-HBs 
Table 1. Published HBV VT rates, infection parameters, and timing of testing

\begin{tabular}{|c|c|c|c|}
\hline Authors & Rate of VT \% (Number infected $/ n$ ) & Seromarkers measured & Timing of measurement \\
\hline Chen et $a .^{9}$ & $2.4(13 / 546)$ & $\mathrm{HBsAg}$, anti-HBc, $\mathrm{HBeAg}$ & $\geq 12$ months old \\
\hline Yu et al. ${ }^{10}$ & $18(6 / 33)$ & HBV DNA & $\geq 7$ months \\
\hline Chen et al. ${ }^{8}$ & $20.5(35 / 171)$ & HBsAg and HBV DNA & At birth (cord blood) \\
\hline \multirow[t]{2}{*}{ Pande et al. ${ }^{11}$} & $4(9 / 213)$ & $\mathrm{HBsAg}$ & At birth \\
\hline & $42(89 / 213)$ & HBV DNA & At birth \\
\hline \multirow[t]{2}{*}{ Chen et al. ${ }^{7}$} & $27.7(41 / 148)$ & HBsAg & $\geq 7$ months \\
\hline & $11.4(17 / 148)$ & HBsAg and HBV DNA & $\geq 7$ months \\
\hline Li et al. ${ }^{12}$ & $9.68(52 / 537)$ & $\mathrm{HBsAg}$ & 7 months \\
\hline Schille et al. ${ }^{13}$ & $1.1(100 / 9252)$ & HBsAg & Up to 24 months \\
\hline Xu et al. ${ }^{14}$ & $45.5(142 / 312)$ & HBsAg, HBV DNA, PBMC HBV DNA & Within 24 hours after birth \\
\hline Zhang et al. ${ }^{16}$ & $5.1 \%(9 / 176)$ & HBsAg & At birth and at 6 months of age \\
\hline Liu et al. ${ }^{15}$ & $3.9(10 / 256)$ & HBsAg, HBV DNA & At birth and at $6-12$ months \\
\hline Gao et al. ${ }^{17}$ & $12.78(51 / 399)$ & HBsAg or HBV DNA & Within 24 hours after birth \\
\hline Mean rate of $\mathbf{V T}$ & 15.7 & - & - \\
\hline
\end{tabular}

negative mothers, and ensured an adequate follow-up period, their recommendations have not become widely accepted.

Another proposed solution is to define infection with seromarker measurement at specific time points. If seromarkers are transient at birth, it may be more accurate to measure HBsAg, HBV DNA, and/or HBeAg at 6 or 12 months of age. ${ }^{1}$ The studies described above also differ in their methods of blood sampling from infants, with sampling from umbilical cord venous blood and femoral venous blood. Moreover, some studies did not specify the exact site of venous blood draw. Zhang et al. ${ }^{18}$ demonstrated no significant difference in seromarkers between blood sampled from the umbilical cord versus the femoral vein. In that study, both types of samples were obtained at birth before administration of immunoprophylaxis. ${ }^{18}$ Based on the similar results, Zhang et $a l .{ }^{18}$ concluded that cord blood sampling may be a more practical method, with regard to easy accessibility at time of birth, safety and reducing needed sticks to the newborn.
The gold standard of diagnosis is HBV DNA detection in neonatal liver tissue; ${ }^{16}$ however, this is not routinely done for practical and ethical reasons.

\section{Mechanisms of VT}

VT of HBV primarily occurs by intrauterine transmission (IUT), accounting for $13-44 \%$ of HBV transmission. ${ }^{19}$ IUT refers to any transmission occurring prior to the onset of labor. There are several potential mechanisms for IUT of HBV including transplacental leakage, ${ }^{10,19,20}$ placental infection, ${ }^{19}$ cellular transmission via peripheral blood mononuclear cells (PBMCs), ${ }^{10,19}$ and germline transmission ${ }^{4,10}$ (Fig. 1).

Although HBsAg and HBV are unable to traverse the placenta, $\mathrm{HBeAg}$ is small enough to cross. ${ }^{6,21}$ When there is damage to the placenta, infectious particles are able to breach the placental barrier.

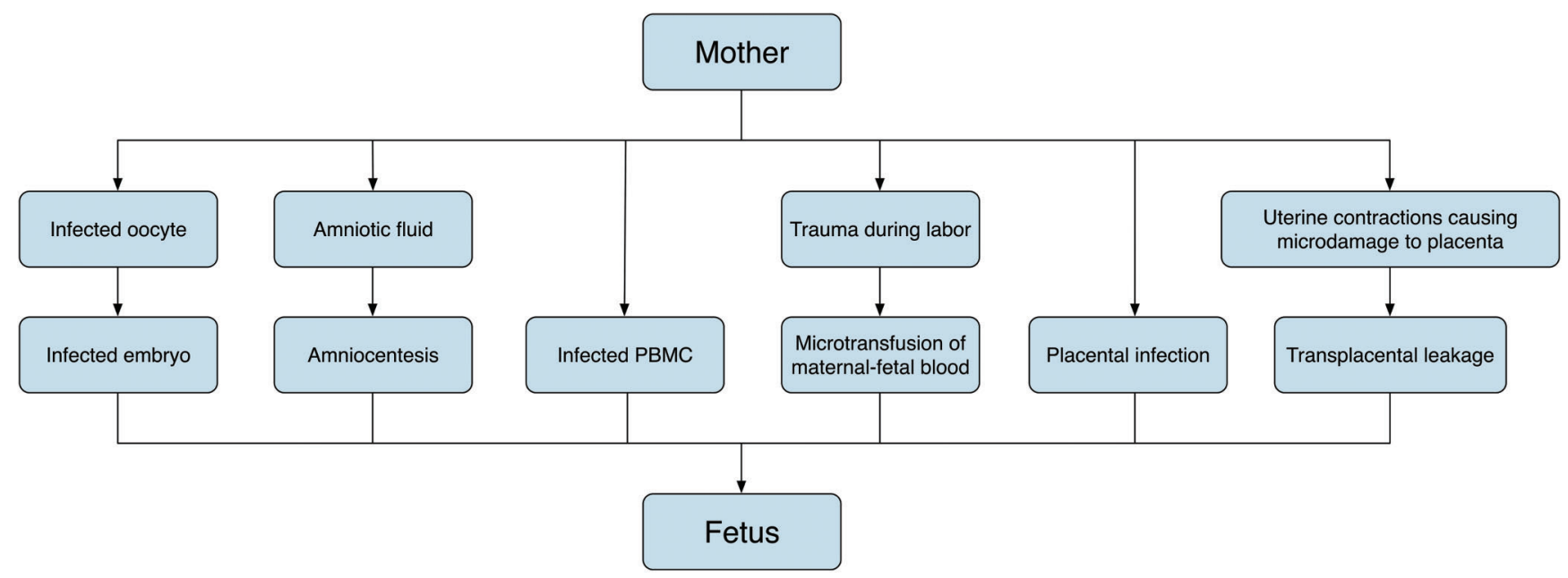

Fig. 1. Mechanisms of HBV VT.

Abbreviation: PBMC, peripheral blood mononuclear cell. 
Transplacental leakage is the most common mode of IUT. ${ }^{22}$ This occurs when there is damage or overt rupture of the placenta, allowing direct exchange of maternal and fetal blood. ${ }^{8}$ Leakage can occur during early pregnancy due to immature placenta or late in pregnancy due to uterine contractions. ${ }^{8,20}$ While many studies support this as the primary mechanism of IUT, others suggest that IUT can occur in the absence of transplacental leakage. ${ }^{8}$ A retrospective study with a sub-group of HBV-positive mothers that underwent elective Cesarean section (C-section) showed VT of HBV in $1.4 \%$ of infants. ${ }^{23}$ The methodology essentially eliminates uterine contraction as the cause of transplacental leakage, suggesting that IUT in these infants came about by means other than transplacental leakage. However, that study's design lacked control for other causes of transplacental leakage.

Additionally, the placenta itself can become infected. A study by Chen et al. ${ }^{8}$ examined individual cell layers within the placenta tissue for HBV infection by detection of intracellular HBV DNA with PCR and in situ hybridization techniques, and of HBsAg and hepatitis B core antigen ( $\mathrm{HBcAg})$ by immunohistochemistry assay. Detection of HBV DNA, HBsAg or $\mathrm{HBCAg}$ was deemed indicative of infected placenta tissue. The authors did not comment on control for contamination of the placental tissue by maternal blood. They did, however, report that the infection rate decreased from decidual layer, the maternal-most layer, to the villous capillary endothelial cells, which are closest to the fetus ${ }^{8}$ (Fig. 2). IUT occurred in $31 \%$ of women with infected placental tissue. ${ }^{8} \mathrm{HBV}$ infection in the decidual cell layer conferred the smallest risk for IUT, whereas HBV infection of the villous capillary endothelial cells was associated with the greatest risk for IUT. ${ }^{8}$ This suggests that the fetus may be infected by direct contact with the infected interfacing placental cells. While this correlation proposes a possible mechanism of layer-by-layer transmission through the placenta, it does not detail the specific cellular process by which HBV reaches the fetus in utero. Despite this lack of detail, the study was well controlled for co-infection and seropositivity among pregnant females and does clearly define their classification of IUT as HBsAg and HBV DNA positivity in the cord blood at birth. This distinction is important for distinguishing IUT from other forms of VT.

HBV DNA has also been identified in PBMCs. Infected PBMCs serve as HBV carriers from mother to fetus. ${ }^{4,14}$ Several studies have shown transfer of infected maternal PBMCs into fetal circulation as a significant mechanism of $\mathrm{VT}^{4,14}$ A case-control study of $312 \mathrm{HBV}$-positive mothers used polymorphic markers to detect trafficking of PBMCs from mother to child. ${ }^{14}$ The investigators identified seromarkers of $\mathrm{HBV}$ in their neonates, finding $\mathrm{HBsAg}$ in $7.7 \%$, HBV DNA in $19.6 \%$ and PBMC HBV DNA in $26.0 \%$ of the offspring. ${ }^{14}$ The number of infants infected by HBV DNA-positive PBMCs was greater than the number of infants positive for both of the other seromarkers. The percentage of infected infants of mothers with HBV DNA-positive PBMCs (57\%) was greater than the percentage of those with HBV DNAnegative PBMCs (46\%). ${ }^{14}$ Methodologically, this study was well done and illustrates a precise mechanism of VT on the cellular level. However, data on this method of VT is fairly limited in the literature. For instance, $\mathrm{Xu}$ et al. ${ }^{14}$ did not comment on the timing of PBMC transfer during the pregnancy nor on survival duration in the newborn. This

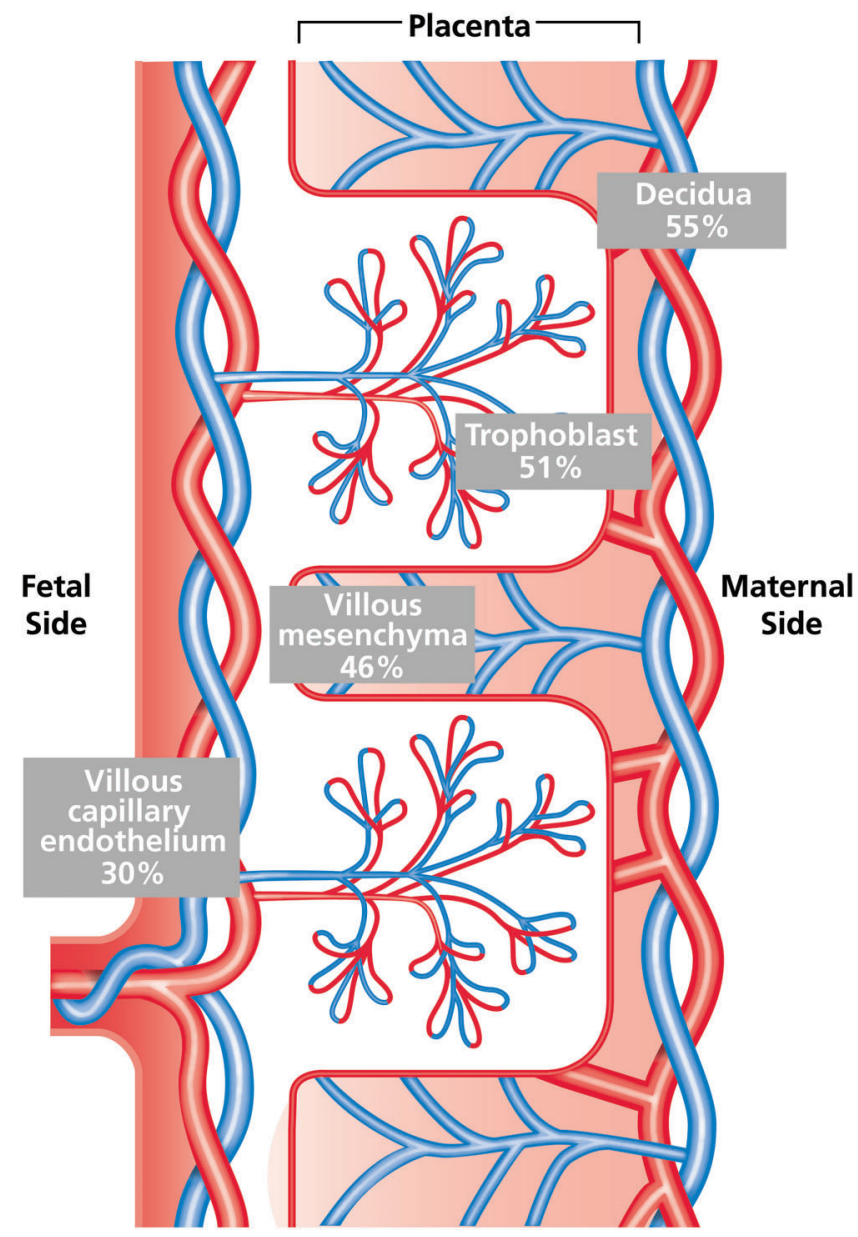

Fig. 2. Placental infection. Depicted here is the percentage of HBV-infected cells per placental layer according to a study by Chen et $a .^{8}$ While the number of cells decreases per layer moving from mother to fetus, there is a greater rate of VT in those with infection in the villous capillary endothelial cells compared to the outermost placental layers.

information would be particularly useful in developing preventive interventions against this form of VT.

Another proposed mechanism of IUT is germline cell transmission. HBV has been shown to infect and replicate within ova. ${ }^{24}$ However, the incorporation of HBV DNA into the germline oocytes may alter its ability to produce a fully functioning virus. ${ }^{24}$ This was demonstrated by a study of 24 newborns born to HBV-positive couples, of which 12 had an HBV-positive oocyte and/or embryo. None of the 12 infants became chronically infected with HBV. ${ }^{24}$ Importantly, that study was conducted exclusively in pregnancies arising from in vitro fertilization and, therefore, the data cannot be generalized to all pregnancies. It is possible that fertilization technique had some impact on viral persistence within the ova. In contrast, Yu et al. ${ }^{10}$ reported a subgroup of two mothers with HBsAg-positive oocytes, both of which produced an infected infant. While these reports demonstrate conflicting results, with $0 \%$ versus $100 \%$ rate of VT by infected oocytes, the sample size in each study was extremely small. It is also difficult to compare techniques for detecting HBsAg within oocytes between these two studies, as the methodology in the study by jin et al. ${ }^{24}$ lacks detailed description of this process. In summary, additional information is 
Mavilia M.G. et al: Vertical transmission of viral hepatitis

required to understand the role of infected germline cells in HBV-positive mothers.

Although technically not considered under the category of VT, sperm to ova transmission has been studied. The proposed mechanism is integration of HBV DNA into the chromosomes of spermatozoa of infected males, which can then be passed on to fertilized embryos. ${ }^{20,24,25}$ Various studies in animal models have confirmed the ability of HBV DNA from spermatozoa to replicate and express HBV proteins in embryos. ${ }^{20}$ Other investigations showed that this may not occur in humans. Cai et al. ${ }^{20}$ identified eight fathers with HBV DNA present in their spermatozoa. None of their infants were infected with $\mathrm{HBV}$, as determined by amniocentesis sampling for HBV seromarkers. In that study, infection occurred only in cases with HBV-positive mothers, regardless of paternal HBV status. ${ }^{20}$ That study was flawed, however, by the ethical issues surrounding amniocentesis, with recruitment limited only to women undergoing the procedure for another approved indication. Indications for amniocentesis are typically associated with higher risk pregnancies and risk for genetic disease, which presents potentially confounding issues in the study sample. Additionally, this was an underpowered study, with a sample of only eight men with HBV-positive spermatozoa. Sperm to ova transmission may be obscured by maternal vaccination, as HBsAb are able to cross the placenta and prevent fetal infection. ${ }^{25}$ This may explain the above findings. It is also possible that sperm to ova transmission is not an actual mechanism of infection.

HBV transmission during the intrapartum period can occur in three ways: instrumental trauma during delivery, microtransfusion of maternal and fetal blood, or by neonatal contact with vaginal fluid or epithelium. ${ }^{4}$ Of note, HBsAg has been identified in $96 \%$ of vaginal fluid samples, and $55-98 \%$ of vaginal epithelial cells. ${ }^{4}$ These specific mechanisms have been confirmed and involve direct contact between the fetus and maternal blood and bodily fluids.

The possibility VT during breastfeeding has been thoroughly disproven in the literature. Although HBV DNA and HBsAg can be detected in breast milk, ${ }^{3,4,9}$ no study to date has demonstrated a statistically significant increase in VT in infants breastfed by HBV-positive mothers. ${ }^{3,9}$ Therefore, HBV-positive mothers should not be advised against breastfeeding. One caveat is any lesion or trauma to the breasts, such as cracked or bleeding nipples, which does increase the risk of HBV transmission. ${ }^{4,9}$ Interestingly, one study comparing breastfed versus formula-fed infants found chronic HBV infection in $1.5 \%$ and $4.7 \%$ respectively. ${ }^{9}$ While this finding achieved only borderline statistical significance $(p=0.063)$, it may suggest a trend toward a protective role of breast milk against chronic HBV infection related to maternal antibodies in breast milk. However, it may also be due to other differences between the breastfed and formula-fed groups. For instance, the data was derived from a sample consisting of mothers who responded to recruitment by invitation. The resulting sample was disproportionately inclined towards breastfeeding as there were more than twice as many breastfed than formula-fed infants. In addition to the borderline significance achieved in this study, there is significant bias in the absence of random sampling.

\section{Risk factors for VT}

While breastfeeding has been excluded as a risk factor for VT, there are many other entities that have been studied as
Table 2. Risk factors for VT of chronic viral hepatitis

\begin{tabular}{|c|c|}
\hline HBV VT & HCV VT \\
\hline $\begin{array}{l}\mathrm{HBeAg}^{12,17,21,26} \\
\text { Maternal viral }\end{array}$ & Maternal viral load $46,48,49,56,57$ \\
\hline $\begin{array}{l}\text { Maternal viral } \\
\text { load }^{1,11,12,15,26,28}\end{array}$ & Elevated maternal ALT level ${ }^{43,56}$ \\
\hline HIV Co-infection ${ }^{31}$ & HIV Co-infection $5,42,43,48,49,57,59$ \\
\hline Neonate sex ${ }^{12}$ & $\begin{array}{l}\text { Obstetric factors: } \\
\text { procedures, PROM, } \\
\text { amniocentesis } 42,43,46,56,57,60\end{array}$ \\
\hline Genotype $^{12}$ & $\begin{array}{l}\text { Maternal IVDU } 50,57 \\
\text { Sex }^{43,57,60}\end{array}$ \\
\hline
\end{tabular}

Abbreviations: PROM, premature rupture of membranes; IVDU, intravenous drug use; ALT, alanine transaminase.

potential risks (Table 2 ). The most prominent risk factors are $\mathrm{HBeAg}$ positivity and high maternal viral load. Other factors that play a lesser role are neonate sex, human immunodeficiency virus (HIV)-HBV co-infection and viral genotype.

$\mathrm{HBeAg}$ positivity is strongly associated with VT of HBV. ${ }^{12,17,21,26}$ The rate of VT is $70-90 \%$ in $\mathrm{HBeAg}$-positive mothers, as compared to $5-40 \%$ without $\mathrm{HBeAg} .{ }^{1,21}$ Young mothers, below the age of 27 years-old, were associated with higher rate of $\mathrm{HBeAg}$ positivity and, therefore, a higher rate of VT. ${ }^{12,13,21}$ Infants born to HBeAg-positive mothers were more likely to become chronically infected with HBV compared to those born to HBeAg-negative mothers. 9,26,27 A study investigating the impact of $\mathrm{HBeAg}$ determined that $9.26 \%$ of infants with $\mathrm{HBeAg}$-positive mothers were diagnosed with chronic HBV infection versus $0.23 \%$ of infants with HBeAgnegative mothers. ${ }^{26}$ This was a well-designed retrospective study with a clear definition of chronic HBV infection, including confirmation of seropositivity at 6 months and a reasonable follow-up period. For these reasons, the authors appeared to be justified in concluding that $\mathrm{HBeAg}$ predicts outcomes of HBV VT.

The association between HBeAg and VT can be explained by two underlying mechanisms. First, $\mathrm{HBeAg}$ is an indicator of increased viral replication, which is directly related to VT. $\mathrm{HBeAg}$ also leads to neonatal tolerance to the virus, resulting in viral chronicity. The ability of HBeAg to cross the placenta generates HBV specific T cell tolerance to the virus. ${ }^{6,19}$ This can ultimately lead to failure of immunoprophylaxis.

Similarly, high maternal viral load at the time of delivery was correlated with VT. ${ }^{11,12,15,16,26,28}$ Several studies quantified viral loads above which there was increased risk, but the results ranged from $10^{5}-10^{8}$ copies/mL. $1,15,16,19,26,28,29$ Gentile et al. ${ }^{1}$ estimated a risk of $3 \%$ for viral load of $10^{6}$ $10^{7}, 7 \%$ for $10^{7}-10^{8}$ and $8 \%$ for greater than $10^{8}$ copies $/ \mathrm{mL}$. In addition, reduction of HBV DNA levels below $10^{6}$ copies $/ \mathrm{mL}$ reduced the risk by about $30 \% .^{30}$

Co-infection with HIV has also been proven to increase risk of VT, with a reported rate of $28 \% .{ }^{31}$ This association is likely mediated by increased HBV viremia caused by HIV immunosuppression. ${ }^{32}$

Male sex may be a risk factor for HBV infection in infants. One study showed VT was more common among male infants, with a ratio of $1.43: 1 .^{12}$ That study also revealed that genotype B2 was most prevalent among cases of VT. ${ }^{12}$ There is very little evidence to support both neonatal sex and viral genotype as risk factors, but they are briefly mentioned here for completeness. 
While the aforementioned factors increase risk of VT, C-section delivery has been shown in a few studies to decrease risk. ${ }^{15,17,23}$ This is a controversial area in both $\mathrm{HBV}$ and $\mathrm{HCV}$ infection. A large retrospective study comparing $\mathrm{C}$-section and vaginal delivery with respect to HBV VT showed rates of $2.1 \%$ versus $5.9 \%$ respectively. ${ }^{15}$ Theoretically, elective $\mathrm{C}$-section decreases the risk of maternal fetal transfusion due to transplacental leakage, and also limits direct contact with maternal genital tract and its secretions. ${ }^{4}$ However, these studies lacked randomization and did not specify control other risk factors, such as $\mathrm{HBeAg}$ status. The majority of the available literature failed to demonstrate a significant difference in risk for VT based on mode of delivery. $8,16,19,26,33$ Ultimately, elective C-section is not currently recommended for $\mathrm{HBsAg}$-positive mothers solely for prevention of $\mathrm{VT}^{33}$

\section{Prevention}

The key to eliminating VT of HBV is adequate screening and preventive measures both during pregnancy and after delivery. All pregnant women should be screened for HBsAg. ${ }^{1} \mathrm{~A}$ positive test result should be followed by HBV DNA quantification and determination of HBeAg status. ${ }^{1}$ This information will reveal any increased risk of VT and inform the clinical decision for initiation of appropriate prophylactic measures. This strategy is depicted in Fig. 3.

Immunoprophylaxis is indicated for all infants born to HBV-positive mothers. The HBV vaccine and hepatitis B immunoglobulin (HBIG) are both used for immunoprophylaxis, although there is some controversy as to whether both are required. Some studies have shown that vaccination alone may be equally effective. ${ }^{6,11,34} \mathrm{~A}$ meta-analysis of nine randomized controlled trials illustrated no difference in HBV VT in infants born to HBsAg-positive/HBeAg-negative mothers who received combined immunization or HBV vaccine alone. ${ }^{34}$ Others have demonstrated a superior prevention rate when these methods are combined. ${ }^{4,13}$ For instance, Schillie et al. ${ }^{13}$ found HBV vaccine to be $75 \%$ effective, and HBIG to be $71 \%$ effective, and with combined efficacy of $94 \%$. There are several potential explanations for the differences seen among these studies. It is likely that the maternal viral load was different among study populations, which would impact the rate of VT despite immunoprophylaxis. None of the above studies delineated the specific mechanism of VT. This could be important because HBIG plays a larger role in the immediate prevention of intrapartum transmission, as compared to IUT. ${ }^{11}$

Currently, the standard of care according to US liver and infectious disease society guidelines is to administer both the HBV vaccine and HBIG. ${ }^{9,11,16,35}$ A total of two doses of HBIG and three doses of HBV vaccine are recommended. The American Association for the Study of Liver Diseases and United States' Centers for Disease Control recommends that first dose of HBV vaccine and HBIG be administered within 24 hours of birth. ${ }^{4,11}$ Any delay beyond 48 hours postpartum significantly decreases efficacy. ${ }^{4}$ Subsequent doses are given at approximately 1 month and then 6 months of age. ${ }^{11,23}$ The second dose of HBIG is administered at 2 weeks of age. ${ }^{23}$ Without immunoprophylaxis, $90 \%$ of infants born to $\mathrm{HBsAg} / \mathrm{HBeAg}$-positive mothers will become infected. ${ }^{22}$ HBIG and HBV vaccine has been reported to reduce the rate of VT from $90 \%$ to $5-10 \% .^{23}$

Immunoprophylaxis has some limitations. It is only effective against infections acquired peripartum. It does not protect

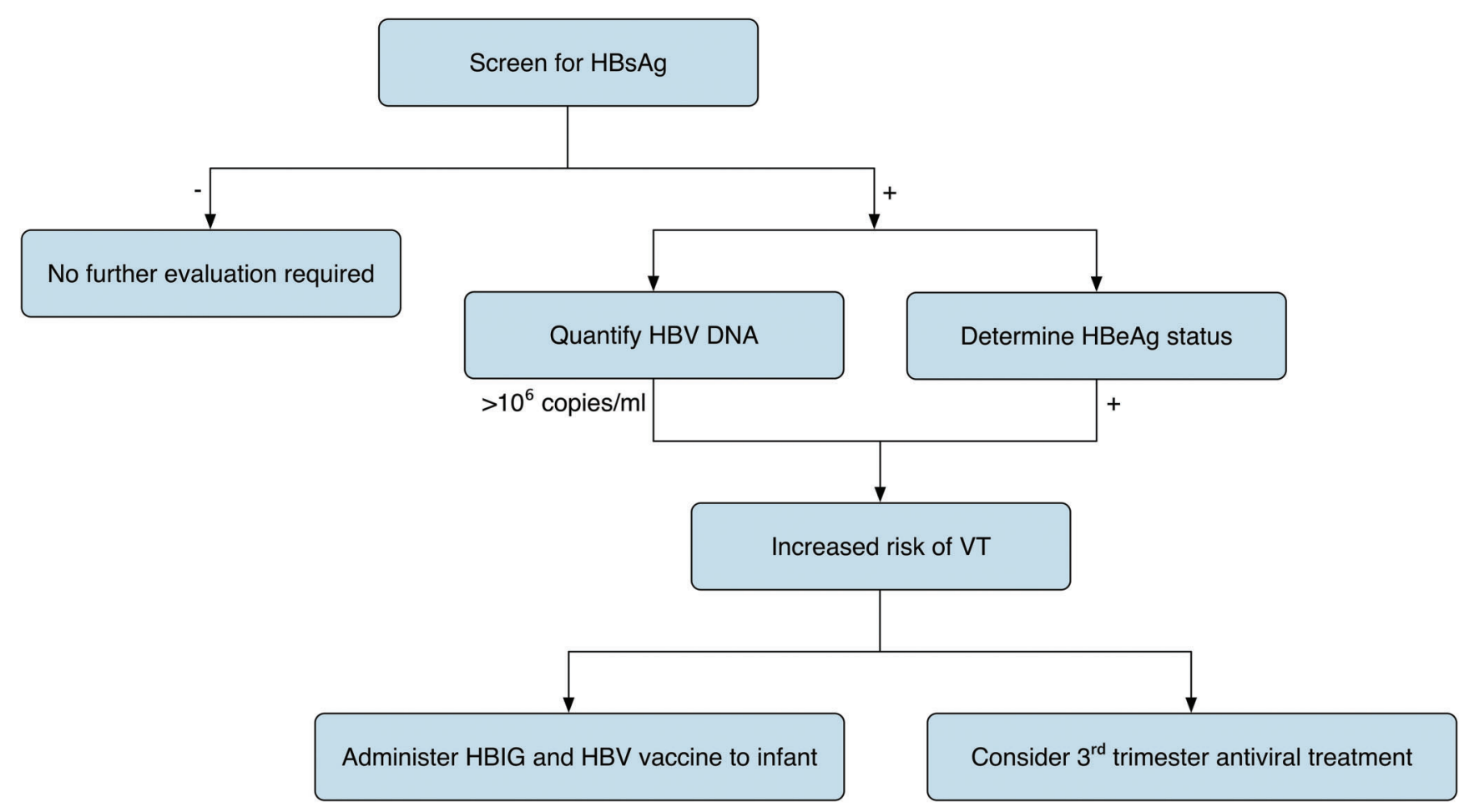

Fig. 3. Screening and prevention of HBV in pregnant females. 
against IUT. ${ }^{4,7}$ HBIG given to mothers in third trimester has not been shown effective in reducing $\mathrm{VT}^{23} \mathrm{~A}$ randomized trial by Yuan et $a l .^{36}$ found no difference in number of infected infants between the intervention group, comprised of pregnant women who received three doses of HBIG in their third trimester, compared to a control group of pregnant women who did not receive any antepartum treatment. Additionally, high maternal viral load and HBeAg positivity have been shown to confer additional risk for immunoprophylaxis failure. ${ }^{37}$ Approximately $5-20 \%$ of children born to highly viremic mothers ${ }^{7,12,23,35}$ and $10 \%$ of infants born to HBeAg-positive mothers ${ }^{26}$ were chronically infected despite timely administration of HBIG.

Unlike HBIG, other preventive strategies effectively decreased the likelihood of VT of HBV when initiated prior to delivery. Antiviral nucleotide/nucleoside analog agents have proven useful in lowering the maternal viral load of HBV and thereby reducing the rate of $\mathrm{VT}^{4,23,26}$ Current practice includes screening women during weeks 28-32 of pregnancy to quantify the HBV DNA. ${ }^{26,37}$

According to the European Association for the Study of Liver, women with HBV DNA of $>10^{6}-10^{7}$ copies $/ \mathrm{mL}$ require additional treatment with antiviral medications to reduce risk of VT. ${ }^{15,29,38} \mathrm{HBeAg}$ positivity has been used as a surrogate for viral load when considering antiviral medications. Therapy should begin in the third trimester. ${ }^{9}$ However, there is some evidence that initiation of antiviral agents after week 32 was insufficient to reduce maternal viral load for a protective effect. ${ }^{35}$ Conversely, starting treatment too early in pregnancy may be problematic, as antivirals started in the first trimester resulted in more birth defects compared to when started during the third trimester. ${ }^{6}$

Only a few nucleotide/nucleoside analogs have been approved for use in pregnancy due to limited availability of safety data (Table 5 ). Lamivudine is a category $C$ nucleoside analog that decreases maternal viral load by competitively inhibiting HBV reverse transcriptase. ${ }^{19,30}$ Several studies have demonstrated greater than $50 \%$ reduction in VT rate in those women treated with lamivudine versus untreated women. ${ }^{4,6} \mathrm{~A}$ meta-analysis of 1693 pregnant women found up to a $70 \%$ reduction in VT in those treated with lamivudine. ${ }^{35,39}$ Recent emergence of lamivudine-resistant HBV strains ${ }^{40}$ has turned attention toward other agents, including telbivudine and tenofovir.

Telbivudine is a category $B$ nucleoside analog that selectively inhibits HBV polymerase and thereby suppresses HBV replication. ${ }^{30} \mathrm{~A}$ number of studies have demonstrated that telbivudine is more effective than lamivudine at reducing maternal viral load. ${ }^{6,12,30,35,41}$ A study comparing mothers treated with lamivudine versus telbivudine found $\mathrm{HBsAg}$ positivity in their children in $18 \%$ and $2 \%$ respectively. ${ }^{6}$ Another study compared the viral load in pregnant women at 4-8 weeks after initiation of antiviral therapy, finding HBV DNA to be undetectable in $36.5 \%$ in those treated with tebivudine and $20.1 \%$ in the lamivudine group. ${ }^{30}$ These findings, in concert with the increased resistance against lamivudine, underscore telbivudine as the superior drug.

A third medication that has been shown to be effective in reducing maternal viral load is tenofovir. ${ }^{1,41}$ Tenofovir is a category B nucleotide analog that selectively inhibits reverse transcriptase. ${ }^{35}$ It has been shown to significantly lower median HBV DNA in pregnant mothers compared to controls. ${ }^{29}$ In this group of mothers receiving tenofovir, $68 \%$ were at the target HBV DNA level of $<200,000 \mathrm{IU} /$ $\mathrm{mL}{ }^{29}$ Data on safety and efficacy of tenofovir are somewhat limited compared to the previously mentioned agents.

While these drugs are effective at preventing VT of HBV, there are no current data available on the long-term safety for children exposed to these drugs in utero. ${ }^{23}$ More longitudinal studies are needed to elucidate any long-term safety concerns associated with these treatments.

\section{HCV}

\section{Epidemiology}

HCV infection affects $2-3 \%$ of the world's population. ${ }^{5,42,43}$ In the United States, $1-2 \%$ of pregnant women are infected, ${ }^{43-45}$ with approximately 40,000 children born to HCV-positive mothers each year. ${ }^{44,46}$ Compared to HBV, the rate of VT in $\mathrm{HCV}$ is lower, ${ }^{2}$ ranging from $3-14 \% \%^{5,42,43,46-55}$ (Table 3 ). More specifically, the risk of VT is $1.7 \%$ in children born to women positive for hepatitis $\mathrm{C}$ antibody (HCAb) and $4.3 \%$ in children born to women positive for HCV RNA. ${ }^{42} \mathrm{HCV}$ acquired by VT progresses to chronic hepatitis $\mathrm{C}$ in greater than $80 \%$ of cases. ${ }^{56}$ Furthermore, there is a $1-2 \%$ risk of cirrhosis with childhood $\mathrm{HCV}_{1}{ }^{49}$ with greater risk of more severe liver disease and more frequent progression to cirrhosis in those with HBV co-infection. ${ }^{45}$

\section{Diagnostic criteria}

Unlike HBV, the diagnostic criteria for VT of HCV infection are well defined. VT of HCV can be confirmed in two ways: HCV RNA detected in two serum samples at least 3 months apart during the first year of life or hepatitis $C$ antibody present after 18 months of age $52,56,57$ (Table 4). A negative HCV RNA

Table 3. Published HCV VT rates, infection parameters, and timing of testing

\begin{tabular}{|c|c|c|c|}
\hline Authors & Rate of VT \% (number infected $/ n$ ) & Seromarkers measured & Timing of measurement \\
\hline Jhaveri et al. ${ }^{48}$ & $14.3(7 / 49)$ & \multirow[t]{6}{*}{ HCV RNA } & 12 months \\
\hline Tejedor et al. ${ }^{60}$ & $2.4(17 / 711)$ & & $\geq 18$ months \\
\hline Garanzzino et al. ${ }^{47}$ & $4.9(45 / 907)$ & & $\geq 18$ months \\
\hline $\begin{array}{l}\text { European Paediatric } \\
\text { HCV Network }\end{array}$ & $6.2(91 / 1479)$ & & $\geq 18$ months \\
\hline El-Kamary et al. ${ }^{55}$ & $12.5 \%(29 / 232)$ & & 2-6 months \\
\hline Kuncio et al..$^{54}$ & $5(4 / 84)$ & & 12 months \\
\hline Mean rate of $\mathbf{V T}$ & 7.6 & - & - \\
\hline
\end{tabular}


Table 4. Diagnostic criteria for HCV VT

1. HCV RNA positive in two samples at least 3 months apart $\leq 1^{\text {st }}$ year of life

2. Hepatitis $C$ antibody positive at $\geq 18$ months of age

result within the first month of life does not rule out HCV infection. The sensitivity of PCR for HCV RNA was found to be only $22 \%$ at birth, but increased to $70-85 \%$ after the first month of life. ${ }^{43}$ The timing of seropositivity may provide information on the timing of transmission. A few studies suggest that an infant that is positive for HCV RNA within the first 3 days of life is likely to have been infected by IUT. ${ }^{43,56}$ If HCV RNA is negative in the first 3 days of life, but later becomes positive, the infant was more likely to have been infected during the intrapartum or postpartum periods. ${ }^{43}$ However, these studies either did not perform testing with cord blood or did not specify their source of neonatal blood sampling, which partially discredits the evidence behind this assumption.

In contrast to HBV, the rate of VT in HCV has clearly defined diagnostic criteria. Consequently, rate of VT in HCV has a much narrower range $(2-14 \%)^{5,42,43,46-55}$ than HBV $(1-28 \%) .^{7-17}$

\section{Mechanisms of VT of HCV}

Like HBV, HCV transmission from mother to infant occurs by IUT or during delivery. ${ }^{42}$ It is estimated that $30 \%$ of cases are intrauterine, whereas $40-50 \%$ of the cases are perinatal. ${ }^{43}$

The fetus may be exposed to HCV as free virions or cellassociated virus that crosses the placenta. ${ }^{43} \mathrm{~A}$ review article by Le Campion et al. ${ }^{58}$ proposed that this occurs by transcytosis, or transcellular vesicular transport (Fig. 4). This is a well-written review summarizing many postulated mechanisms of VT. The authors discussed several risk factors for VT as mechanisms for transmission.

Gugliano et $a .^{2}$ found that primary trophoblast, a specialized epithelial layer of the placenta, expresses receptors for HCV binding and entry (Figs. 4 and 5). The authors further demonstrated the presence of HCV NS5A protein, a nonstructural HCV protein, within human trophoblast cells, suggesting endocytosis and uptake of $\mathrm{HCV}^{2}$ This was a meticulously designed study, which effectively demonstrated this mechanism of transmission. Moreover, this study is unique in its inclusion of samples from both first and second trimester placentas of terminated pregnancies, as well as full term placentas. Placental samples from all three trimesters should have allowed for temporal analysis of transmission and an understanding of the timing with which VT occurs during gestation, but timing was not analyzed in this study.

A large amount of HCV reaches the placenta during pregnancy. ${ }^{43}$ The placental infection leads to release of inflammatory cytokines and activates the maternal immune response. ${ }^{44}$ This ultimately can cause damage to the placental barrier between mother and fetus and creates an avenue for HCV transmission ${ }^{44}$ (Fig. 4).

During delivery, there is ample opportunity for the infant to be exposed to infected maternal blood. This contact can occur incidentally during childbirth. Various obstetrical procedures can cause this mixing of maternal and fetal blood.

As with $\mathrm{HBV}$, the question of breastfeeding as a potential mechanism of HCV VT has been raised. Small amounts of HCV RNA can be detected in breast milk. ${ }^{5,49,56}$ However, the literature unanimously concludes that there is no risk of transmission via breast milk. ${ }^{5,46,56,57,59}$ As with $\mathrm{HBV}$, the exception is the case of damaged nipples, which would allow for blood contact between mother and infant and pose a risk for transmission. ${ }^{56}$ Some studies have shown that the virus is actually inactivated by human milk and its digestion products. $^{54,59}$ The lipase in human milk degrades triglycerides and the break-down products form micelles. ${ }^{59}$ These then disrupt the viral envelope and inactivate the HCV. ${ }^{59}$ While this is an interesting finding, the conclusions cannot be applied to breastfeeding for HCV-positive mothers, as the study was limited to breast milk from HCV-negative mothers, and then incubated with the virus. This preparation of virus mixed with breast milk may differ from breast milk produced by HCV-positive women in amount of virus present or in viral integrity.

Table 5. Third trimester antiviral therapy

\begin{tabular}{|c|c|c|c|}
\hline & Lamivudine & Telbivudine & Tenofovir \\
\hline Drug class & Nucleoside analog & Nucleoside analog & Nucleotide analog \\
\hline Category & C & B & B \\
\hline Mechanism & $\begin{array}{l}\text { Competitive inhibitor of HBV } \\
\text { reverse transcriptase }\end{array}$ & $\begin{array}{l}\text { Selective inhibitor of } \\
\text { HBV polymerase }\end{array}$ & $\begin{array}{l}\text { Selective inhibitor of HBV } \\
\text { reverse transcriptase }\end{array}$ \\
\hline Dosing & 100-150 mg daily & 600 mg daily & 300 mg daily \\
\hline Risks \& benefit & Increased resistance & Fewer side effects & Limited safety data \\
\hline Common side effects & $\begin{array}{l}\text { Headache, fatigue, } \\
\text { neuropathy, insomnia, } \\
\text { nausea, vomiting, } \\
\text { pancreatitis, abdominal } \\
\text { pain, neutropenia, elevates } \\
\text { transaminases, myalgia, } \\
\text { cough }\end{array}$ & Fatigue, increased CPK & $\begin{array}{l}\text { Insomnia, headache, pain, } \\
\text { dizziness, skin rash, } \\
\text { hyperlipidemia, abdominal } \\
\text { pain, nausea, vomiting, } \\
\text { diarrhea, decreased bone } \\
\text { mineral density, increased } \\
\text { CPK, weakness, fever }\end{array}$ \\
\hline
\end{tabular}

Abbreviation: CPK, creatine phosphokinase. 


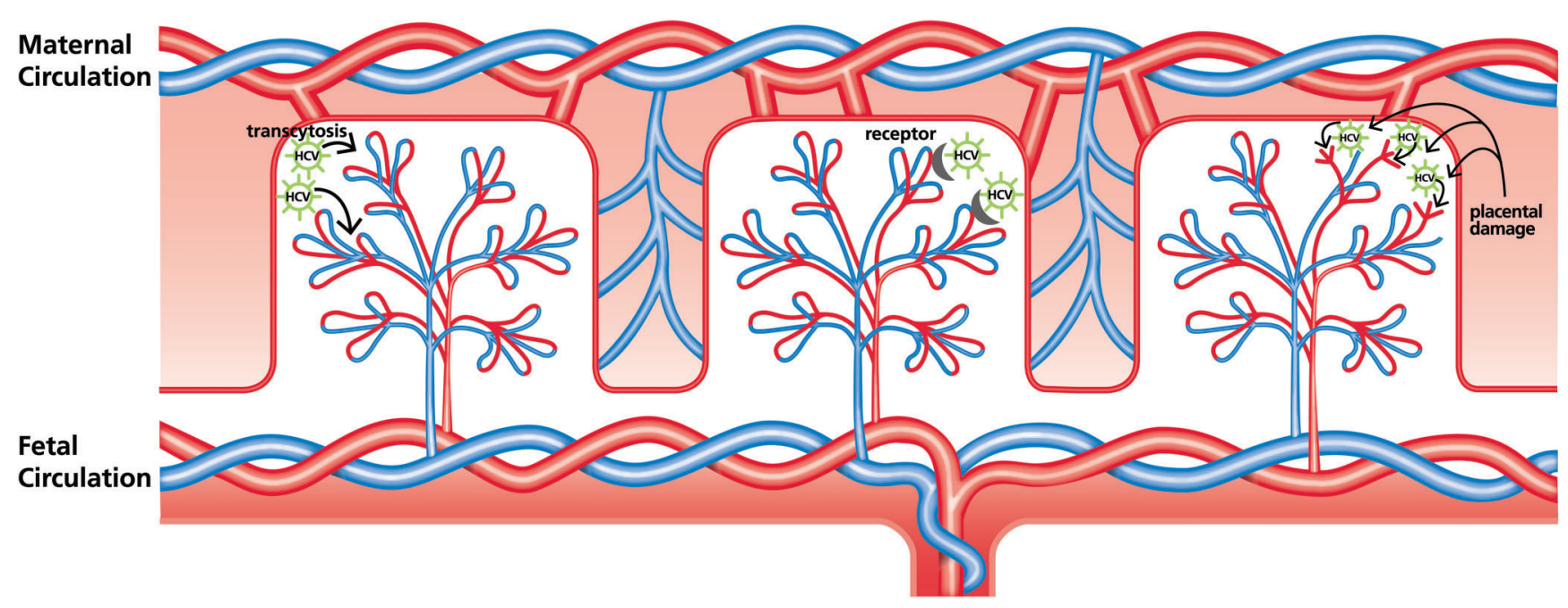

Fig. 4. Proposed mechanisms of HCV VT.

*Adapted from Giugliano et al. ${ }^{2}$ and Le Camption et al. ${ }^{58}$

\section{Risk factors for $\mathrm{VT}$}

There are many factors that can increase the risk of HCV VT, including viral load, maternal characteristics, obstetrical factors, sex of neonate and co-infection with HIV (Table 2). The most important risk factor for VT of HCV is maternal viral load. $46,48,49,56,57$ High maternal viral load at the time of delivery is strongly correlated with risk of VT. ${ }^{46,48}$ No clear level of HCV RNA has been defined as predictive of VT. However, VT has been reported even with HCV RNA levels <20,000 IU/ $\mathrm{mL} .{ }^{48}$ Interestingly, one study found the rate of VT in pregnant women with undetectable levels of HCV RNA to be $0.06 \% .{ }^{60}$ Although this is very low, it should theoretically be zero. This can be explained by the definition of "undetectable" used in this particular study.

There are several maternal characteristics that contribute to risk of VT. High maternal alanine aminotransferase level within 1 year of pregnancy or at the time of delivery is associated with VT. ${ }^{43,56}$ This association can be explained by viral load. Elevated level of alanine aminotransferase likely

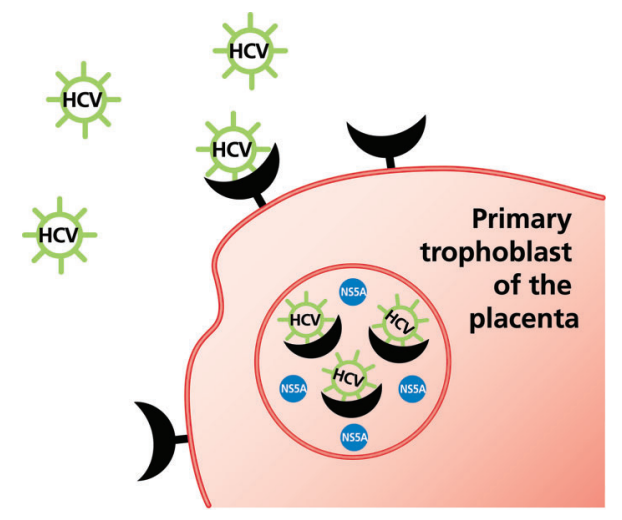

Fig. 5. Transmission of HCV by receptor binding uptake. reflects high viral replication, ${ }^{37,43,56}$ which has been clearly linked to increased risk of VT. History of intravenous drug use in mothers has also been suggested in a few studies as a possible risk factor, but this association has not been reported consistently throughout the literature. ${ }^{50,57}$

A number of obstetrical considerations may also play a role in VT of HCV, including intrapartum procedures, amniocentesis, prolonged rupture of membranes (ROM), and multiple births. Fetal scalp blood sampling, internal electrode fetal monitoring, and episiotomy are commonly performed during childbirth. These procedures increase maternal fetal blood exposure and ultimately increase the risk for VT. ${ }^{43,56,60}$ More specifically, fetal scalp blood sampling and internal electrode monitoring increased risk of VT from 1.9 to $9.3 \%$ in one study. ${ }^{60}$ Episiotomy increased the risk from 1.7 to $3.8 \% .60$ Amniocentesis is another obstetric procedure that can increase risk of VT iatrogenically. HCV can be detected in the amniotic fluid of $6.3 \%$ of infected mothers. ${ }^{56}$ This procedure allows for potential exposure of the HCV present in amniotic fluid to fetal circulation. Prolonged ROM, or the duration of time from rupture of the amniotic sac to delivery of the fetus, more specifically for duration greater than 6 hours may increase the risk of VT. $42,43,46,56,60$ The European Pediatric Hepatitis C Virus Network estimates that for every hour increase in ROM duration, the risk of VT increases by $3 \% .57$ The average ROM time in infected children is 4.5 hours. ${ }^{57}$ Also, from an obstetrical perspective, VT of HCV does not equally affect infants of twin pregnancies. Transmission is more likely to occur in the twin with second birth order. ${ }^{56}$ This is likely because the second twin has more perinatal exposure to maternal circulation due to the aforementioned risk factors.

As in the case of HBV, sex of the neonate has been reported to affect the rate of VT in HCV. However, male infants are more commonly infected with $\mathrm{HBV}$, while female infants are twice as likely to be infected with HCV. ${ }^{43,57,60}$ It is speculated that this is due to differences in hormonal or genetic response to $\mathrm{HCV}^{60}$ 
Pregnant females co-infected with HIV are 3 to 4 times more likely to transmit HCV to their child, ${ }^{42,43,48,49}$ with the reported VT rate being up to $19 \% .^{5}$ In these individuals, HIV-induced immunosuppression allows for increased HCV replication and, therefore, higher viral load. ${ }^{49,57,59}$ Treatment with highly active antiretroviral therapy reduces the increased risk of VT. $43,57,59$

Several other factors have been studied for the potential to influence VT of HCV, but have actually been found to confer no additional risk. History of VT in previous pregnancy does not increase the risk of VT in subsequent deliveries. ${ }^{56,57}$ There was no association between mode of delivery and rate of VT. ${ }^{48,57}$ More specifically, C-section does not prevent VT of $\mathrm{HCV}^{46,48,49}$ Lastly, no specific viral genotype has been linked to risk for $\mathrm{VT}^{42,56}$ Of note, genotype 1 has been reported to be the most prevalent genotype among infected children, ranging from $53-75 \%$ of cases. ${ }^{47,48,60}$ While a relationship to genotype is possible, it more likely reflects the overall distribution of genotype in the general population.

\section{Prevention}

Unlike HIV and HBV infection, there are no antiviral medications or vaccines available for HCV-positive pregnant women to reduce or prevent $\mathrm{VT}^{43}$ Antiviral medications developed against HCV are contraindicated during pregnancy. ${ }^{43,46}$ Pegylated interferon increases the risk of miscarriage and low birth weight. ${ }^{45}$ Ribavirin, a direct teratogen, is not only contraindicated in pregnant women, but also in the male partners of women who may become pregnant ${ }^{43,45}$ Newer agents, including sofosbuvir and ledipasvir, are not necessarily contraindicated in pregnancy. However, their effects and safety have not yet been adequately studied during pregnancy in humans ${ }^{50,51}$ and, therefore, these agents are not used in this population.

Because no intervention has been shown safe and effective, the key to prevention of HCV VT is screening. HCV screening should be incorporated into the routine care of women of childbearing age. HCV-positive females may then be treated prior to conception to eliminate the risk of transmission.

\section{Discussion}

This is the first review to our knowledge to address VT in both HBV and HCV. It provides an opportunity to consider VT of chronic viral hepatitis as a unified clinical dilemma and to identify the similarities and differences between each virus with regard to mechanisms of transmission, risk factors, and prevention.

$\mathrm{VT}$ is the most common route of transmission of chronic viral hepatitis in children. It can occur by several mechanisms. Both HBV and HCV transmission can occur during intrauterine and intrapartum periods. HCV can itself can cross normal, intact placenta as can HBV antigens filtered according to size, whereas HBV particles cannot. Neither infection is transmitted by breast milk. Similarly, the mode of delivery is not associated with VT of either virus, and C-section is not recommended for infected mothers solely to prevent VT. In addition, HBV and $\mathrm{HCV}$ share some common risk factors for VT including maternal viral load, HIV co-infection and neonatal sex.

Some children are able to clear both HBV and HCV spontaneously. However, there is a significant portion of infected children with persistent viral hepatitis following VT.
This highlights the importance of prevention of VT in both HBV and HCV. There is sharp contrast between HBV and HCV prevention, with more preventive options available for HBV infection, including HBV vaccine, HBIG, and third trimester antiviral medications. There are currently no vaccines or antiviral regimens approved for use during pregnancy or in children for HCV. Screening before and during pregnancy is a viable method for either virus.

\section{Conclusions}

As treatments for adult chronic viral hepatitis improves, the rates of VT should simultaneously be reduced. In the meantime, it is crucial to further our current understanding of how each virus is transmitted, how it affects children from infancy through adulthood, and how we can better prevent these cases of VT.

\section{Acknowledgement}

This work was made possible by the Herman Lopata Chair in Hepatitis Research, and a grant from Alexion Corp. We are also grateful to Peg Atkinson Lee for assistance in the production of the original graphics included in this publication.

\section{Conflict of interest}

The authors have no conflict of interests related to this publication.

\section{Author contributions}

Drafting of the manuscript and development of figures (MGM), proposing concept for the review and revising the manuscript with critical revisions (GYW).

\section{References}

[1] Gentile I, Borgia G. Vertical transmission of hepatitis B virus: challenges and solutions. Int J Womens Health 2014;6:605-611. doi: 10.2147/IJWH. S51138.

[2] Giugliano S, Petroff MG, Warren BD, Jasti S, Linscheid C, Ward A, et al. Hepatitis $C$ virus sensing by human trophoblasts induces innate immune responses and recruitment of maternal NK cells: potential implications for limiting vertical transmission. J Immunol 2015;195:3737-3747. doi: 10. 4049/jimmunol.1500409.

[3] Wang T, Wang M, Duan G, Chen X, He Y. Discrepancy in impact of maternal milk on vertical transmission between Hepatitis $B$ virus and Human cytomegalovirus. Int J Infect Dis 2015;37:1-5. doi: 10.1016/j.ijid.2015.06.002.

[4] Pan CQ, Duan ZP, Bhamidimarri KR, Zou HB, Liang XF, Li J, et al. An algorithm for risk assessment and intervention of mother to child transmission of hepatitis B virus. Clin Gastroenterol Hepatol 2012;10:452-459. doi: 10.1016/j. cgh.2011.10.041.

[5] Schaefer EAK, Dienstag JL. Viral hepatitis. Scientific American Medicine, 2014.

[6] Trehanpati N, Hissar S, Shrivastav S, Sarin SK. Immunological mechanisms of hepatitis B virus persistence in newborns. Indian J Med Res 2013;138: 700-710.

[7] Chen T, Wang J, Feng Y, Yan Z, Zhang T, Liu M, et al. Dynamic changes of HBV markers and HBV DNA load in infants born to $\mathrm{HBsAg}(+)$ mothers: can positivity of HBsAg or HBV DNA at birth be an indicator for HBV infection of infants? BMC Infect Dis 2013;13:524. doi: 10.1186/1471-2334-13-524.

[8] Chen Y, Wang L, Xu Y, Liu X, Li S, Qian Q, et al. Role of maternal viremia and placental infection in hepatitis $B$ virus intrauterine transmission. Microbes Infect 2013;15:409-415. doi: 10.1016/j.micinf.2013.02.008.

[9] Chen X, Chen J, Wen J, Xu C, Zhang S, Zhou YH, et al. Breastfeeding is not a risk factor for mother-to-child transmission of hepatitis $B$ virus. PLoS One 2013;8:e55303. doi: 10.1371/journal.pone.0055303. 
[10] Yu M, Jiang $\mathrm{Q}, \mathrm{Gu} X$, Ju L, Ji Y, Wu K, et al. Correlation between vertical transmission of hepatitis $B$ virus and the expression of HBsAg in ovarian follicles and placenta. PLoS One 2013;8:e54246. doi: 10.1371/journal. pone.0054246.

[11] Pande C, Sarin SK, Patra S, Kumar A, Mishra S, Srivastava S, et al. Hepatitis B vaccination with or without hepatitis $B$ immunoglobulin at birth to babies born of HBsAg-positive mothers prevents overt HBV transmission but may not prevent occult HBV infection in babies: a randomized controlled trial. J Viral Hepat 2013;20:801-810. doi: 10.1111/jvh.12102.

[12] Li Z, Xie Z, Ni H, Zhang Q, Lu W, Yin J, et al. Mother-to-child transmission of hepatitis $B$ virus: evolution of hepatocellular carcinoma-related viral mutations in the post-immunization era. J Clin Virol 2014;61:47-54. doi: 10. $1016 / j . j c v .2014 .06 .010$.

[13] Schillie S, Walker T, Veselsky S, Crowley S, Dusek C, Lazaroff J, et al. Outcomes of infants born to women infected with hepatitis B. Pediatrics 2015; 135:e1141-e1147. doi: 10.1542/peds.2014-3213.

[14] Xu YY, Liu HH, Zhong YW, Liu C, Wang Y, Jia LL, et al. Peripheral blood mononuclear cell traffic plays a crucial role in mother-to-infant transmission of hepatitis B virus. Int J Biol Sci 2015;11:266-273. doi: 10.7150/ijbs.10813.

[15] Liu CP, Zeng YL, Zhou M, Chen LL, Hu R, Wang L, et al. Factors associated with mother-to-child transmission of hepatitis $B$ virus despite immunoprophylaxis. Intern Med 2015;54:711-716. doi: 10.2169/internalmedicine.54. 3514.

[16] Zhang Z, Li A, Xiao X. Risk factors for intrauterine infection with hepatitis B virus. Int J Gynaecol Obstet 2014;125:158-161. doi: 10.1016/j.ijgo.2013. 10.028.

[17] Gao Y, Guo J, Zhang F, Guo Z, Zhang LR, Wang T, et al. Evaluation of neonatal Toll-like receptors $3(\mathrm{c} .1377 \mathrm{C} / \mathrm{T})$ and $9(\mathrm{G} 2848 \mathrm{~A})$ gene polymorphisms in HBV intrauterine transmission susceptibility. Epidemiol Infect 2015;143: 1868-1875. doi: 10.1017/S0950268814002921.

[18] Zhang L, Gui XE, Wang B, Fan JY, Cao Q, Mullane K, et al. Serological positive markers of hepatitis $B$ virus in femoral venous blood or umbilical cord blood should not be evidence of in-utero infection among neonates. BMC Infect Dis 2016;16:408. doi: 10.1186/s12879-016-1754-1.

[19] Ma L, Alla NR, Li X, Mynbaev OA, Shi Z. Mother-to-child transmission of HBV: review of current clinical management and prevention strategies. Rev Med Virol 2014;24:396-406. doi: 10.1002/rmv.1801.

[20] Cai QX, Zhu YY. Is hepatitis B virus transmitted via the male germ line? A seroepidemiological study in fetuses. Int J Infect Dis 2013;17:e54-e58. doi: $10.1016 / j$.ijid.2012.09.002.

[21] Ott J], Stevens GA, Wiersma ST. The risk of perinatal hepatitis B virus transmission: hepatitis $B$ e antigen ( $\mathrm{HBeAg}$ ) prevalence estimates for all world regions. BMC Infect Dis 2012;12:131. doi: 10.1186/1471-2334-12-131.

[22] Chang MH. Hepatitis B virus infection. Semin Fetal Neonatal Med 2007;12: 160-167. doi: 10.1016/j.siny.2007.01.013.

[23] Pan CQ, Zou HB, Chen Y, Zhang $X$, Zhang H, Li J, et al. Cesarean section reduces perinatal transmission of hepatitis $B$ virus infection from hepatitis $B$ surface antigen-positive women to their infants. Clin Gastroenterol Hepatol 2013;11:1349-1355. doi: 10.1016/j.cgh.2013.04.026.

[24] Jin L, Nie R, Li Y, Xiao N, Zhu L, Zhu G. Hepatitis B surface antigen in oocytes and embryos may not result in vertical transmission to offspring of hepatitis B virus carriers. Fertil Steril 2016;105:1010-1013. doi: 10.1016/j.fertnstert.2015.12.008.

[25] Cao LH, Li YR, Wang SY, Liu ZM, Sun SC, Xu DB, et al. Effect of hepatitis B vaccination in hepatitis $B$ surface antibody-negative pregnant mothers on the vertical transmission of hepatitis $B$ virus from father to infant. Exp Ther Med 2015;10:279-284. doi: 10.3892/etm.2015.2483.

[26] Wen WH, Chang MH, Zhao LL, Ni YH, Hsu HY, Wu JF, et al. Mother-to-infant transmission of hepatitis $\mathrm{B}$ virus infection: significance of maternal viral load and strategies for intervention. J Hepatol 2013;59:24-30. doi: 10.1016/j. jhep.2013.02.015.

[27] Tian Y, Kuo CF, Akbari O, Ou JH. Maternal-Derived Hepatitis B Virus e Antigen Alters Macrophage Function in Offspring to Drive Viral Persistence after Vertical Transmission. Immunity 2016;44:1204-1214. doi: 10.1016/j.immuni. 2016.04.008.

[28] Lu LL, Chen BX, Wang J, Wang D, Ji Y, Yi HG, et al. Maternal transmission risk and antibody levels against hepatitis $B$ virus e antigen in pregnant women. Int J Infect Dis 2014;28:41-44. doi: 10.1016/j.ijid.2014.07.028.

[29] Pan CQ, Duan Z, Dai E, Zhang S, Han G, Wang Y, et al. Tenofovir to prevent hepatitis B transmission in mothers with high viral load. N Engl J Med 2016; 374:2324-2334. doi: 10.1056/NEJMoa1508660.

[30] Yu MM, Jiang $\mathrm{O}$, Ji Y, Wu KH, Ju LL, Tang $X$, et al. Comparison of telbivudine versus lamivudine in interrupting perinatal transmission of hepatitis $B$ virus. J Clin Virol 2014;61:55-60. doi: 10.1016/j.jcv.2014.06.005.

[31] Chotun N, Nel E, Cotton MF, Preiser W, Andersson MI. Hepatitis B virus infection in HIV-exposed infants in the Western Cape, South Africa. Vaccine 2015; 33:4618-4622. doi: 10.1016/j.vaccine.2015.06.076.

[32] Chasela CS, Kourtis AP, Wall P, Drobeniuc J, King CC, Thai H, et al. Hepatitis B virus infection among HIV-infected pregnant women in Malawi and trans- mission to infants. J Hepatol 2014;60:508-514. doi: 10.1016/j.jhep.2013. 10.029.

[33] Hu Y, Chen J, Wen J, Xu C, Zhang S, Xu B, et al. Effect of elective cesarean section on the risk of mother-to-child transmission of hepatitis $B$ virus. BMC Pregnancy Childbirth 2013;13:119. doi: 10.1186/1471-2393-13-119.

[34] Machaira M, Papaevangelou V, Vouloumanou EK, Tansarli GS, Falagas ME. Hepatitis $B$ vaccine alone or with hepatitis $B$ immunoglobulin in neonates of $\mathrm{HBsAg}+/ \mathrm{HBeAg}-$ mothers: a systematic review and meta-analysis. J Antimicrob Chemother 2015;70:396-404. doi: 10.1093/jac/dku404.

[35] Sarkar M, Terrault NA. Ending vertical transmission of hepatitis B: the third trimester intervention. Hepatology 2014;60:448-451. doi: 10.1002/hep. 27145.

[36] Yuan J, Lin J, Xu A, Li H, Hu B, Chen J, et al. Antepartum immunoprophylaxis of three doses of hepatitis $B$ immunoglobulin is not effective: a single-centre randomized study. J Viral Hepat 2006;13:597-604. doi: 10.1111/j.13652893.2006.00738.x.

[37] Elefsiniotis IS, Tsoumakas K, Kapritsou M, Magaziotou I, Derdemezi A, T MS, et al. Liver function tests in viremic and nonviremic chronic hepatitis B virus-infected pregnant women: importance of alanine aminotransferase/sodium ratio. Gastroenterol Nurs 2013;36:422-428. doi: 10.1097/SGA. 0000000000000004.

[38] European Association For The Study Of The Liver. EASL. clinical practice guidelines: Management of chronic hepatitis B virus infection. J Hepatol 2012;57:167-185. doi: 10.1016/j.jhep.2012.02.010.

[39] Han L, Zhang HW, Xie JX, Zhang Q, Wang HY, Cao GW. A meta-analysis of lamivudine for interruption of mother-to-child transmission of hepatitis $B$ virus. World J Gastroenterol 2011;17:4321-4333. doi: 10.3748/wjg.v17. i38.4321.

[40] Thio CL, Guo N, Xie C, Nelson KE, Ehrhardt S. Global elimination of motherto-child transmission of hepatitis $\mathrm{B}$ : revisiting the current strategy. Lancet Infect Dis 2015;15:981-985. doi: 10.1016/S1473-3099(15)00158-9.

[41] Njei B, Gupta N, Ewelukwa O, Ditah I, Foma M, Lim JK. Comparative efficacy of antiviral therapy in preventing vertical transmission of hepatitis $\mathrm{B}$ : a network meta-analysis. Liver Int 2016;36:634-641. doi: 10.1111/liv. 12959.

[42] Benova L, Mohamoud YA, Calvert C, Abu-Raddad LJ. Vertical transmission of hepatitis $C$ virus: systematic review and meta-analysis. Clin Infect Dis 2014; 59:765-773. doi: 10.1093/cid/ciu447.

[43] Tosone G, Maraolo AE, Mascolo S, Palmiero G, Tambaro O, Orlando R. Vertical hepatitis $C$ virus transmission: Main questions and answers. World $\mathrm{J}$ Hepatol 2014;6:538-548. doi: 10.4254/wjh.v6.i8.538.

[44] Hurtado CW, Golden-Mason L, Brocato M, Krull M, Narkewicz MR, Rosen HR. Innate immune function in placenta and cord blood of hepatitis C-seropositive mother-infant dyads. PLoS One 2010;5:e12232. doi: 10.1371/journal. pone.0012232.

[45] Pawlowska M, Domagalski K, Pniewska A, Smok B, Halota W, Tretyn A. What's new in hepatitis $C$ virus infections in children? World J Gastroenterol 2015;21:10783-10789. doi: 10.3748/wjg.v21.i38.10783.

[46] Cottrell EB, Chou R, Wasson N, Rahman B, Guise JM. Reducing risk for mother-to-infant transmission of hepatitis $C$ virus: a systematic review for the U.S. Preventive Services Task Force. Ann Intern Med 2013;158:109113. doi: 10.7326/0003-4819-158-2-201301150-00575.

[47] Garazzino S, Calitri C, Versace A, Alfarano A, Scolfaro C, Bertaina C, et al. Natural history of vertically acquired HCV infection and associated autoimmune phenomena. Eur J Pediatr 2014;173:1025-1031. doi: 10.1007/ s00431-014-2286-6.

[48] Jhaveri R, Hashem M, El-Kamary SS, Saleh DA, Sharaf SA, El-Mougy F, et al. Hepatitis $C$ virus ( $\mathrm{HCV}$ ) vertical transmission in 12-month-old infants born to $\mathrm{HCV}$-infected women and assessment of maternal risk factors. Open Forum Infect Dis 2015;2:ofv089. doi: 10.1093/ofid/ofv089.

[49] Jhaveri R, Swamy GK. Hepatitis C Virus in Pregnancy and Early Childhood: Current Understanding and Knowledge Deficits. J Pediatric Infect Dis Soc 2014;3 Suppl 1:S13-S18. doi: 10.1093/jpids/piu045.

[50] Aebi-Popp K, Duppenthaler A, Rauch A, De Gottardi A, Kahlert C. Vertical transmission of hepatitis $C$ : towards universal antenatal screening in the era of new direct acting antivirals (DAAs)? Short review and analysis of the situation in Switzerland. J Virus Erad 2016;2:52-54.

[51] Kanninen $T$, Dieterich $D$, Asciutti $S$. HCV vertical transmission in pregnancy: New horizons in the era of DAAs. Hepatology 2015;62:1656-1658. doi: 10. 1002/hep.28032.

[52] El-Guindi MA. Hepatitis C viral infection in children: updated review. Pediatr Gastroenterol Hepatol Nutr 2016;19:83-95. doi: 10.5223/pghn.2016.19. 2.83 .

[53] Koneru A, Nelson N, Hariri S, Canary L, Sanders KJ, Maxwell JF, et al. Increased hepatitis $\mathrm{C}$ virus (HCV) detection in women of childbearing age and potential risk for vertical transmission - United States and Kentucky, 2011-2014. MMWR Morb Mortal Wkly Rep 2016;65:705-710. doi: 10. 15585/mmwr.mm6528a2. 
[54] Kuncio DE, Newbern EC, Johnson CC, Viner KM. Failure to test and identify perinatally infected children born to hepatitis $C$ virus-infected women. Clin Infect Dis 2016;62:980-985. doi: 10.1093/cid/ciw026.

[55] El-Kamary SS, Hashem M, Saleh DA, Abdelwahab SF, Sobhy M, Shebl FM, et al. Hepatitis $C$ virus-specific cell-mediated immune responses in children born to mothers infected with hepatitis C virus. J Pediatr 2013;162:148154. doi: 10.1016/j.jpeds.2012.06.057.

[56] Indolfi G, Resti M. Perinatal transmission of hepatitis $C$ virus infection. J Med Virol 2009;81:836-843. doi: 10.1002/jmv.21437.

[57] European Paediatric Hepatitis C. Virus Network. A significant sex-but not elective cesarean section-effect on mother-to-child transmission of hepatitis C virus infection. J Infect Dis 2005;192:1872-1879. doi: 10.1086/ 497695.
[58] Le Campion A, Larouche A, Fauteux-Daniel S, Soudeyns H. Pathogenesis of hepatitis $C$ during pregnancy and childhood. Viruses 2012;4:3531-3550. doi: $10.3390 / v 4123531$.

[59] Tovo PA, Calitri C, Scolfaro C, Gabiano C, Garazzino S. Vertically acquired hepatitis $C$ virus infection: Correlates of transmission and disease progression. World J Gastroenterol 2016;22:1382-1392. doi: 10.3748/wjg.v22.i4. 1382.

[60] Garcia-Tejedor A, Maiques-Montesinos V, Diago-Almela VJ, Pereda-Perez A, Alberola-Cuñat $\mathrm{V}$, López-Hontangas $\mathrm{JL}$, et al. Risk factors for vertical transmission of hepatitis C virus: a single center experience with $710 \mathrm{HCV}-$ infected mothers. Eur J Obstet Gynecol Reprod Biol 2015;194:173-177. doi: 10.1016/j.ejogrb.2015.09.009. 